\title{
Serum metabolomic profile in genetically modified cows carrying human $\alpha$-lactalbumin gene
}

\author{
QIN WANG $^{1 *}$, WEI FU $^{1 *}$, XIAOFEI LIU ${ }^{1}$, JIANWU WANG $^{2}$, CHUNYAN FENG $^{1}$, SONGYIN QIU $^{1}$, \\ XIAOLIN LI ${ }^{1}$, DANDAN LIU ${ }^{1}$, SHUIFANG ZHU ${ }^{1}$ and XIANGMEI LIN ${ }^{1}$ \\ ${ }^{1}$ Chinese Academy of Inspection and Quarantine, Beijing Economic-Technological Development Area, \\ Beijing 100176; ${ }^{2}$ Wuxi Kingenew Biotech Co., Ltd., Beijing 100193, P.R. China
}

Received September 12, 2016; Accepted May 22, 2017

DOI: $10.3892 / \mathrm{mmr} .2017 .7768$

\begin{abstract}
The present study aimed to investigate the serum metabolomic profiles in genetically modified cows carrying and expressing human lactalbumin $\alpha(L A L B A)$ and non- $L A L B A$ cows, and identify altered metabolic characteristics following the genetic modification. Serum biochemistry indexes were measured according to protocols recommended by International Federation of Clinical Chemistry. The metabolomic profiles were determined using the serum samples collected from $L A L B A(\mathrm{n}=6)$ and non-LALBA cows $(n=6)$. Welch's two-sample t-test was used to identify the metabolites that significantly differed between the $L A L B A$ and non- $L A L B A$ groups (fold-change $\neq 1$ and $\mathrm{P}<0.05$ ), followed by random forest and pathway analysis. The serum biochemistry indexes of $L A L B A$ and non- $L A L B A$ cows were within the normal ranges of healthy cows. A total of 273 metabolites were detected, among which 79 metabolites, including 46 increased and 33 decreased metabolites, differed significantly between the $L A L B A$ and non-LALBA groups. Random forest analysis identified 30 potential key metabolites, including 14 elevated and 16 reduced metabolites. These metabolites were primarily involved in pathways concerning the metabolism of leucine, isoleucine, valine, tryptophan and lipids, such as myristate and eicosapentaenoate. However, the serum in $L A L B A$ cow had unique metabolomic signature compared with non- $L A L B A$ cows. The accumulation of polyunsaturated fatty acids and amino acids, and the reduced levels of long chain saturated fatty acids in serum may benefit $L A L B A$ cows. However,
\end{abstract}

Correspondence to: Dr Xiangmei Lin or Dr Shuifang Zhu, Chinese Academy of Inspection and Quarantine, Beijing Economic-Technological Development Area, 11 Building, Ronghua South Road, Daxing, Beijing 100176, P.R. China

E-mail: linxm@caiq.gov.cn

E-mail: zhusf@caiq.gov.cn

*Contributed equally

Key words: lactalbumin $\alpha$, metabolomic profile, serum, genetically modified cow, tryptophan further investigations are required to validate these benefits and the corresponding mechanisms.

\section{Introduction}

Lactalbumin $\alpha$ has important nutritional and physiological value: i) It contains numerous essential amino acids, especially tryptophan, and benefits cognitive function and muscle protein synthesis; ii) it interacts with $\beta$-1,4-galactosyltransferase to promote lactose synthesis, and thereby facilitates milk production and secretion (1); iii) it binds divalent cations like $\mathrm{Ca}$ and $\mathrm{Zn}$ and facilitates mineral absorption (1); iv) it exerts strong gastroprotective activity via stimulating mucus metabolism and increasing thickness of the mucus gel layer; v) its digested peptides have immunostimulatory and antibacterial properties, and thus possibly protect against infection (1) and iv) its folding variants can induce tumor apoptosis and remedy cutaneous warts.

In contrast with its abundancy in human milk (25-35\% of total protein) (2), lactalbumin $\alpha$ only accounts for $2-5 \%$ of the total protein in cow milk (1). In addition, endogenous cow lactalbumin $\alpha$ is one of the major allergens for humans. In order to increase the concentration of human lactalbumin $\alpha$ in cow milk, genetically modified cows expressing human lactalbumin $\alpha$ have been developed with the highest content up to $1.55 \mathrm{mg} / \mathrm{ml}$ in milk (3). Subsequently, previous studies have investigated the effect overexpression or transgenesis of human lactalbumin $\alpha$ on the protein expression profile and milk composition in cows, as well as the environmental risks. Reportedly, overexpression of human lactalbumin $\alpha$ in cows does not affect milk composition (4). It has been determined that 166 proteins in the milk fat globule membrane (MFGM) were specifically expressed only in cows overexpressing human lactalbumin $\alpha$ and this was different from the cloned non-transgenic cows and conventionally bred normal cows (5). A previous study performed a functional analysis that revealed that the up and downregulated proteins in MFGM of cows overexpressing human lactalbumin $\alpha$ were not associated with a specific biological pathway or function and that human lactalbumin $\alpha$ overexpression had no deleterious effects on the cattle mammary gland (5). Additionally, the transgene of human lactalbumin $\alpha(L A L B A)$ cannot be detected in gut microbial DNA and thus has no influence 
on microbial communities in cow gut or soil. However, the effect of transgenic modification on the metabolomic profile in cow serum remains to be elucidated. As somatic cell nuclear transfer was performed during the genetic modification in a previous study (3), LALBA was expressed in all the somatic cells of the transgenic cows, including blood cells. The presence of non-inherent $L A L B A$ may abnormally regulate gene expression via endogenous microRNAs or transcription factors and thus change the metabolomic profile of cow serum. This is the hypothesis and rationale behind the present study.

Metabolomics has been successfully used to investigate genetically modified organisms like transgenic rat models of various diseases and genetically engineered goats that produce human lysozyme (hLZ) in their milk (6). It is of note that when the serum metabolomics of hLZ goats (lactating does) and controls were compared, one metabolite was significantly different (6). The present study characterized and compared serum metabolomic profiles in cows carrying and expressing human LALBA (LALBA cows) and non-LALBA cows. The findings of the present study may indirectly reflect the health condition of the LALBA cows and provide complement evidence for the future use of genetic modification in cows. The humanization of bovine milk requires additional investigation of multiple transgenesis in future studies, and the findings of the present study may also contribute to the humanization of bovine milk.

\section{Materials and methods}

Transgenic cloning of Chinese Holstein cow. The protocol of the present study was approved by the Institutional Animal Care and Use Committee of the Chinese Academy of Inspection and Quarantine (Beijing, China). The transgenic cloned Chinese Holstein cow (F0 generation, female) was provided by the China Agricultural University (Beijing, China), which expressed and characterized the bioactive recombinant human lactalbumin $\alpha$ in cow milk (3). It is of note that only human lactalbumin $\alpha$ was genetically overexpressed in the cow referenced in Wang et al (3); however, human LALBA was expressed in all the somatic cells of this cow. Both the $\angle A L B A$ and non- $L A L B A$ cows used in the present study were the offspring of the Wang et al transgenic cow.

LALBA and non-LALBA cows. The primary generation of transgenic cloned cows was defined as the F0 generation (1 female). Following superovulation, the ovum of F0 generation (female) was inseminated with the sperm from one healthy male cattle. Embryos were transferred to ten recipient cows, and a healthy F1 generation (male) was selected, which expressed $L A L B A$. The sperm from the F1 generation (male) was used to artificially inseminate with the ova in 20 normal cows during their child-bearing periods, which were similar in genetic background, age and feeding conditions. In this way, $L A L B A$ and non-LALBA cows (F2 generation, female) were generated, which were identified by using polymerase chain reaction (PCR). The processes of superovulation, embryo transfer, and artificial insemination were performed as previously described (7).
To eliminate genetic background noise and reduce the influence of embryo transfer and cloning process, only half-sibs (F2 generation, female) with the same father (F1 generation, male) were used in the present study. All cows in the present study were similar in genetic background, sex (female) and age ( $\sim 22$ months), and were housed under same conditions (temperature of $14^{\circ} \mathrm{C}$ and $60 \%$ relative humidity) and had the same diet. Additionally, all the cows used were not lactating and none of them were pregnant.

$D N A$ extraction and PCR. PCR was performed to identify the $L A L B A$ and non- $L A L B A$ cows. Total DNA was extracted from $5 \mathrm{ml}$ cow blood samples (namely, pellets following centrifugation at 3,500 x g for $30 \mathrm{~min}$ at $4^{\circ} \mathrm{C}$ ) by using GenElute Blood Genomic DNA kit (Sigma-Aldrich, Merck Millipore, Darmstadt, Germany). The $25 \mu \mathrm{l}$ PCR system consisted of $12.5 \mu 12 \mathrm{X}$ Mix solution including buffer, dNTPs and rTaq polymerase (Takara Biotechnology Co., Ltd., Dalian, China), $1 \mu 1$ forward primer (AGAGAGCACAGTGTTTGG; Invitrogen; Thermo Fisher Scientific, Inc., Waltham, MA, USA) and $1 \mu \mathrm{l}$ reverse primer (GTCCAGCAGGTAAGTAAGG; Invitrogen; Thermo Fisher Scientific, Inc.), $1 \mu \mathrm{l}$ DNA sample, and $9.5 \mu \mathrm{l}$ $\mathrm{ddH}_{2} \mathrm{O}$. The PCR conditions were $95^{\circ} \mathrm{C}$ for $10 \mathrm{~min}$ then 30 cycles $\left(95^{\circ} \mathrm{C}, 30 \mathrm{sec} ; 60^{\circ} \mathrm{C}, 30 \mathrm{sec} ; 72^{\circ} \mathrm{C}, 30 \mathrm{sec}\right)$ and extension at $72^{\circ} \mathrm{C}$ for $30 \mathrm{~min}$. Furthermore, PCR products were electrophoresed on a 1.5\% agarose gel (Takara Biotechnology Co., Ltd.).

RNA extraction, reverse transcription (RT)-PCR and sequencing. RT-PCR and sequencing were performed to validate the transcription of $L A L B A$ in $L A L B A$ cows. Total RNA was extracted from cow blood samples by using Blood RNA mini kit (Qiagen, Hilden, Germany), and reverse transcription was performed using a cDNA synthesis kit (Tiangen Biotech Co., Ltd., Beijing, China). Then, PCR was conducted and cDNA was amplified using Taq PCR Mater Mix kit (Qiagen), forward primer (5'-GGTTCAGTGGTAGACAATCG-3'; Invitrogen; Thermo Fisher Scientific, Inc.), and reverse primer (5'-GGTAAGGAGAAGGAGGATGG-3'; Invitrogen; Thermo Fisher Scientific, Inc.). The conditions of PCR and electrophoresis were as aforementioned and the corresponding products were sequenced. Following alignment, the sequences of these products were consistent with that of $\angle A L B A$, confirming the transcription of $L A L B A$ in $\angle A L B A$ cows.

Serum samples. Blood samples $(5 \mathrm{ml})$ were obtained from the jugular vein of $6 L A L B A$ cows ( $L A L B A$ group) and 6 non- $L A L B A$ cows (non- $L A L B A$ group) at 10:00 am after the animals were fasted for $10 \mathrm{~h}$. After storing the blood at $4{ }^{\circ} \mathrm{C}$ for $12 \mathrm{~h}$, blood samples were centrifuged at 3,500 $\mathrm{x}$ for $30 \mathrm{~min}$ at $4^{\circ} \mathrm{C}$. The supernatant was used as serum samples, which were maintained at $-80^{\circ} \mathrm{C}$ until processing.

Serum biochemistry indexes. In order to detect the effect of $\angle A L B A$ on the blood chemistry of cows, serum biochemistry indexes were quantified, including potassium, sodium, chlorine, calcium, phosphorus, glucose, cholesterol, albumin, total bilirubin, creatine phosphokinase, glutamyl transpeptidase, blood urea nitrogen, alanine aminotransferase and creatinine. These indexes were detected according to the protocols 

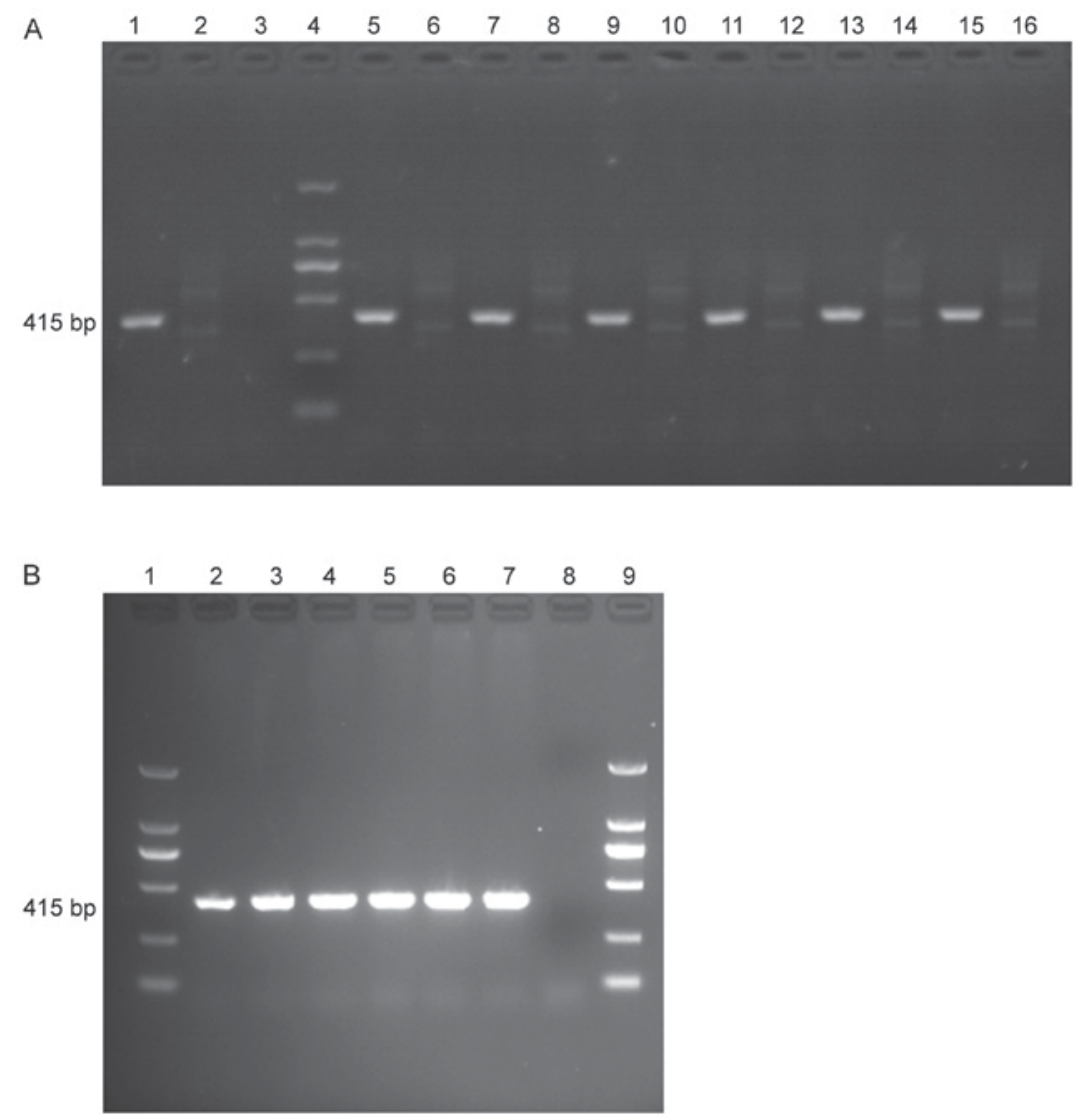

Figure 1. PCR and RT-PCR products of $L A L B A$ and non- $L A L B A$ cows. (A) PCR products. 1, positive control; 2, negative control; 3, blank control; 4, DL2000 marker; 5, 7, 9, 11, 13, 15, samples from $L A L B A$ cows; $6,8,10,12,14,16$, samples from non-LALBA cows. (B) RT-PCR products. 1, DL2000 marker; 2, 3, 4, 5, 6, 7, samples from $L A L B A$ cows; 8, blank control; 9, DL2000 marker. $L A L B A$, human lactalbumin $\alpha$; PCR, polymerase chain reaction; RT, reverse transcription.

recommended by the International Federation of Clinical Chemistry (IFCC) (8).

Metabolite detection. Sample preparation, metabolite extraction and metabolite detection were performed by the SJTU-Metabolon Joint Metabolomics Laboratory (Metabolon Inc., Durham, NC, USA; project no. SJTUX-02-14VW) based on a global unbiased platform. The metabolite detection, data processing, metabolite quantitation and corresponding instrumentation have been were performed as previously described (9). Briefly, the samples were prepared by using Hamilton MicroLab STAR system and the resulting extract was divided and prepared by using TurboVap (Zymark, Palo Alto, CA, USA) and vacuum drying machine for the following instrument: i) Ultra-Performance Liquid Chromatography-Tandem Mass Spectrometry (UPLC-MS/MS) with positive ion mode electrospray ionization (Waters Acquity UPLC and Thermo-Finnigan LTQ mass spectrometer; scan range, $80-1000 \mathrm{~m} / \mathrm{z}$ ); ii) UPLC-MS/MS with negative ion mode electrospray ionization; iii) Liquid Chromatography (LC) polar platform; iv) Gas Chromatography-Mass Spectroscopy (GC-MS, Thermo-Finnigan Trace DSQ fast-scanning single-quadrupole mass spectrometer; scan range, $50-750 \mathrm{~m} / \mathrm{z}$ ). Data were extracted using Metabolon's hardware and software (10) constructed via Microsoft's NET technologies and compounds were identified based on Metabolon library recording $\mathrm{m} / \mathrm{z}$, retention time/index, and chromatographic data of more than 3,300 molecules.
Principal component analysis (PCA). As an unsupervised clustering approach, PCA reduces the dimension of data based on orthogonal transformation, generating principle components (11). In the present study, SIMCA-P version 12.0 (Umetrics AB, Umea, Sweden) was used to perform the PCA.

Hierarchical clustering analysis. As an unsupervised method for clustering data, hierarchical clustering may reveal the large-scale differences between groups based on Euclidean distance. Hierarchical clustering analysis was conducted by using pheatmap package in $\mathrm{R}$ (version 0.7.7; R Core Team, Vienna, Austria) (12).

Altered metabolite screening. In order to generate metabolite levels, peaks were quantified using area-under-the-curve. The metabolite levels were $\log _{10}$ transformed, while missing values were imputed by using the minimum observed value for each compound. The Welch's two-sample t-test (13) was used to identify significantly altered metabolites, namely, the metabolites that significantly differed between $L A L B A$ and non-LALBA groups. The threshold criteria used for this analysis were $\mathrm{P}<0.05$ and fold-change $\neq 1$.

Random forest analysis. As a supervised classification approach based on decision trees (14), random forest analysis is a valuable statistical tool for compound classification (15). Random forest has several advantages: i) It makes no parametric assumptions; ii) variable selection is not required; 
Table I. Serum biochemistry indexes of $L A L B A$ and non- $L A L B A$ cows.

\begin{tabular}{lcrr}
\hline Index & Normal range $^{\mathrm{a}}$ & LALBA & non-LALBA \\
\hline $\mathrm{K}, \mathrm{mmol} / \mathrm{l}$ & $3.9-5.8$ & $4.07 \pm 0.47$ & $4.84 \pm 0.53$ \\
$\mathrm{Na}, \mathrm{mmol} / \mathrm{l}$ & $132-152$ & $140.95 \pm 3.46$ & $141.55 \pm 5.57$ \\
$\mathrm{Cl}, \mathrm{mmol} / \mathrm{l}$ & $97-111$ & $104.17 \pm 3.79$ & $103.70 \pm 3.96$ \\
$\mathrm{Ca}, \mathrm{mmol} / \mathrm{l}$ & $2.1-2.67$ & $2.51 \pm 0.17$ & $2.49 \pm 0.14$ \\
$\mathrm{P}, \mathrm{mmol} / \mathrm{l}$ & $1.3-2.65$ & $1.82 \pm 0.48$ & $2.08 \pm 0.15$ \\
$\mathrm{GLU}, \mathrm{mmol} / \mathrm{l}$ & $2.5-6.0$ & $4.24 \pm 0.10$ & $4.12 \pm 0.25$ \\
$\mathrm{CHO}, \mathrm{mmol} / \mathrm{l}$ & $1.58-5.9$ & $2.87 \pm 1.24$ & $3.22 \pm 0.65$ \\
$\mathrm{ALB}, \mathrm{g} / \mathrm{l}$ & $25-38$ & $34.85 \pm 1.75$ & $34.83 \pm 2.49$ \\
$\mathrm{TBIL}, \mu \mathrm{mol} / \mathrm{l}$ & $0-8.6$ & $5.58 \pm 1.05$ & $7.08 \pm 1.33$ \\
$\mathrm{CK}, \mathrm{U} / \mathrm{l}$ & $76-376$ & $197.33 \pm 67.03$ & $168.83 \pm 164.08$ \\
$\mathrm{GGT}, \mathrm{U} / \mathrm{l}$ & $9-39$ & $19.00 \pm 5.06$ & $23.17 \pm 4.80$ \\
$\mathrm{BUN}, \mathrm{mmol} / \mathrm{l}$ & $1.4-15.7$ & $3.54 \pm 0.49$ & $4.58 \pm 0.20$ \\
$\mathrm{ALT}, \mathrm{U} / \mathrm{l}$ & $11-40$ & $30.50 \pm 5.44$ & $22.00 \pm 6.67$ \\
$\mathrm{CRE}, \mu \mathrm{mol} / \mathrm{l}$ & $55-130$ & $119.97 \pm 10.92$ & $128.30 \pm 5.30$ \\
\hline
\end{tabular}

LALBA, human lactalbumin $\alpha$; SD, standard deviation; GLU, glucose; CHO, cholesterol; ALB, albumin; TBIL, total bilirubin; CK, creatine phosphokinase; GGT, glutamyl transpeptidase; BUN, blood urea nitrogen; ALT, alanine aminotransferase; CRE, creatinine. ${ }^{\text {anNormal range }}$ values of serum biochemistry indexes were obtained from Ma et al (18).

A

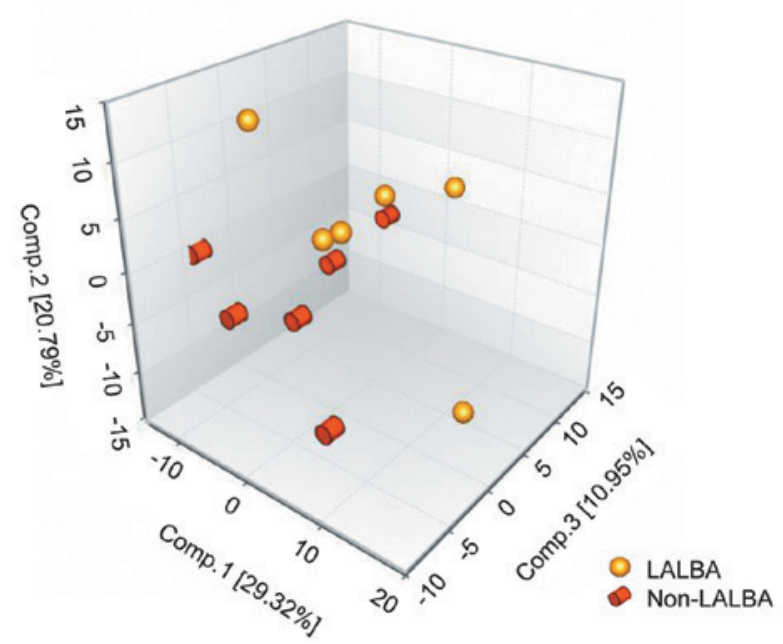

B

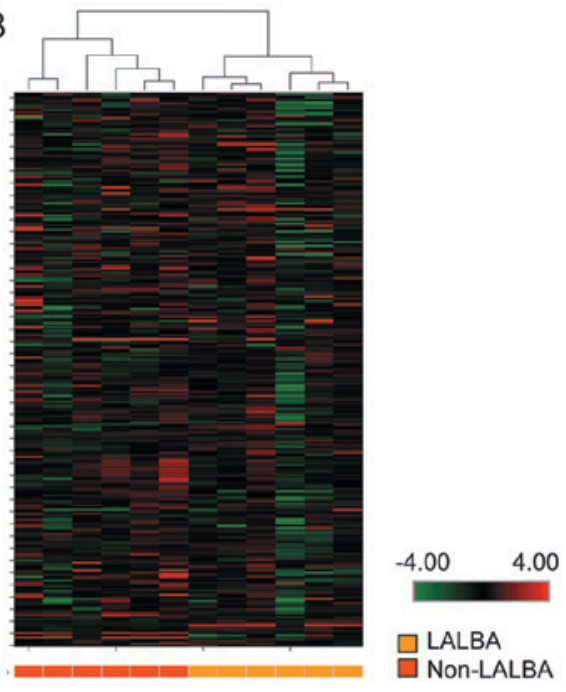

Figure 2. Distinct separation between $L A L B A$ and non- $L A L B A$ groups. (A) Principal component analysis and (B) hierarchical clustering analysis. $L A L B A$, human lactalbumin $\alpha$.

iii) it does not overfit; iv) it is invariant to transformation and v) it is fairly easy to implement in R. The present study used the randomForest package (16) to perform random forest analysis. To identify the metabolites making a large contribution to classification, parameter 'variable importance' was computed, and random forest analysis provides an 'importance' rank ordering of metabolite based on mean decrease accuracy.

Pathway analysis. The significantly altered metabolites were mapped onto general biological pathways using the Pathview software package (version 1.8.0; bioconductor.org/ packages/release/bioc/html/pathview.html) (17) in R, generating the potential pathways affected by $L A L B A$ transgenesis.

\section{Results}

LALBA and non-LALBA cows. The presence of LALBA and $\angle A L B A$ mRNA in $L A L B A$ cows was confirmed by using PCR (Fig. 1A) and RT-PCR (Fig. 1B) and the quantity of $L A L B A$ and $L A L B A$ mRNA in the $6 L A L B A$ cows were similar (Fig. 1).

Serum biochemistry indexes. Although differences of some serum biochemistry indexes occurred between $L A L B A$ and non- $L A L B A$ cows, all of the serum biochemistry indexes of 
Table II. Significantly altered metabolites between $L A L B A$ and non- $L A L B A$ cows.

\begin{tabular}{|c|c|c|}
\hline Metabolite name & $\begin{array}{c}L A L B A / \\
\text { non- } L A L B A\end{array}$ & P-value \\
\hline $\mathrm{N}$-acetylglycine & 0.63 & $0.0002^{\mathrm{a}}$ \\
\hline 3-methylhistidine & 0.75 & 0.0107 \\
\hline Lysine & 1.76 & 0.0247 \\
\hline Pipecolate & 1.52 & 0.0246 \\
\hline Phenyllactate (PLA) & 0.30 & $0.0005^{\mathrm{a}}$ \\
\hline 4-hydroxyphenylacetate & 1.66 & 0.0090 \\
\hline Tyrosine & 1.45 & 0.0159 \\
\hline $\begin{array}{l}\text { 4-hydroxyphenylacetyl } \\
\text { glycine }\end{array}$ & 1.91 & $0.0001^{\mathrm{a}}$ \\
\hline Tryptophan & 1.38 & 0.0184 \\
\hline Indolepropionate & 0.34 & 0.0073 \\
\hline 3-indoxyl sulfate & 1.71 & $0.0008^{\mathrm{a}}$ \\
\hline C-glycosyltryptophan & 0.76 & 0.0248 \\
\hline Leucine & 1.32 & 0.0320 \\
\hline$\beta$-hydroxyisovalerate & 0.28 & $0.0004^{\mathrm{a}}$ \\
\hline$\alpha$-hydroxyisovalerate & 0.50 & 0.0087 \\
\hline Isoleucine & 1.27 & 0.0199 \\
\hline 2-methylbutyrylcarnitine (C5) & 0.45 & 0.0110 \\
\hline 2-methylbutyrylglycine & 0.59 & $0.0043^{\mathrm{a}}$ \\
\hline 3-hydroxy-2-ethylpropionate & 0.39 & $0.0007^{\mathrm{a}}$ \\
\hline Valine & 1.44 & 0.0040 \\
\hline Isobutyrylcarnitine & 0.68 & $0.0047^{\mathrm{a}}$ \\
\hline$\alpha$-hydroxyisocaproate & 0.34 & $0.0002^{\mathrm{a}}$ \\
\hline 2-aminobutyrate & 1.46 & 0.0468 \\
\hline S-methylcysteine & 1.60 & $0.0012^{\mathrm{a}}$ \\
\hline Arginine & 1.33 & $0.0001^{\mathrm{a}}$ \\
\hline Urea & 0.73 & 0.0482 \\
\hline Ornithine & 2.48 & $0.0091^{\mathrm{a}}$ \\
\hline N-methyl proline & 0.31 & $0.0033^{\mathrm{a}}$ \\
\hline Guanidinoacetate & 1.68 & 0.0284 \\
\hline$\gamma$-glutamyltyrosine & 1.49 & $0.0009^{\mathrm{a}}$ \\
\hline$\gamma$-glutamylvaline & 1.40 & 0.0327 \\
\hline Glycylleucine & 1.64 & 0.0384 \\
\hline Leucylleucine & 1.67 & 0.0331 \\
\hline Leucyltryptophan & 2.70 & $0.0003^{\mathrm{a}}$ \\
\hline 1,5-anhydroglucitol (1,5-AG) & 0.49 & 0.0023 \\
\hline Xylitol & 1.38 & 0.0112 \\
\hline Lactose & 0.27 & 0.0473 \\
\hline Erythronate & 0.76 & 0.0282 \\
\hline Myristate (14:0) & 0.69 & 0.0427 \\
\hline Myristoleate (14:1n5) & 0.22 & $0.0003^{\mathrm{a}}$ \\
\hline Palmitoleate (16:1n7) & 0.61 & 0.0165 \\
\hline $\begin{array}{l}\text { Eicosapentaenoate } \\
(\mathrm{EPA} ; 20: 5 \mathrm{n} 3)\end{array}$ & 1.68 & $0.0070^{\mathrm{a}}$ \\
\hline $\begin{array}{l}\text { Docosapentaenoate } \\
\text { (n3 DPA; 22:5n3) }\end{array}$ & 1.36 & 0.0387 \\
\hline Mead acid (20:3n9) & 1.60 & 0.0053 \\
\hline Hexadecanedioate & 1.66 & 0.0179 \\
\hline Docosadioate & 1.48 & 0.0476 \\
\hline 2-aminooctanoate & 0.45 & 0.0217 \\
\hline
\end{tabular}

Table II. Continued.

\begin{tabular}{|c|c|c|}
\hline Metabolite name & $\begin{array}{c}L A L B A / \\
\text { non- } L A L B A\end{array}$ & $\mathrm{P}$-value \\
\hline Butyrylcarnitine & 0.78 & 0.0174 \\
\hline Acetylcarnitine & 0.68 & 0.0046 \\
\hline Deoxycarnitine & 1.38 & $0.0015^{\mathrm{a}}$ \\
\hline 3-dehydrocarnitine & 0.57 & $0.0007^{\mathrm{a}}$ \\
\hline Myo-inositol & 0.66 & 0.0416 \\
\hline Choline & 1.17 & 0.0369 \\
\hline $\begin{array}{l}\text { 1-palmitoleoylglycero- } \\
\text { phosphocholine (16:1) }\end{array}$ & 2.20 & 0.0219 \\
\hline $\begin{array}{l}\text { 1-margaroylglycero- } \\
\text { phosphocholine (17:0) }\end{array}$ & 2.65 & 0.0236 \\
\hline $\begin{array}{l}\text { 2-stearoylglycero- } \\
\text { phosphocholine }\end{array}$ & 2.33 & 0.0442 \\
\hline $\begin{array}{l}\text { 2-oleoylglycero- } \\
\text { phosphocholine }\end{array}$ & 2.04 & 0.0387 \\
\hline $\begin{array}{l}\text { 1-palmitoylplasmenylethano- } \\
\text { lamine }\end{array}$ & 2.16 & 0.0401 \\
\hline $\begin{array}{l}\text { 1-palmitoylglycero- } \\
\text { phosphoethanolamine }\end{array}$ & 2.67 & 0.0048 \\
\hline $\begin{array}{l}\text { 1-stearoylglycero- } \\
\text { phosphoethanolamine }\end{array}$ & 2.42 & $0.0014^{\mathrm{a}}$ \\
\hline $\begin{array}{l}\text { 1-oleoylglycero- } \\
\text { phosphoethanolamine }\end{array}$ & 2.52 & $0.0149^{a}$ \\
\hline $\begin{array}{l}\text { 1-arachidonoylglycero- } \\
\text { phosphoethanolamine }\end{array}$ & 1.69 & $0.0115^{\mathrm{a}}$ \\
\hline Glycerol & 0.73 & $0.0006^{\mathrm{a}}$ \\
\hline Cholate & 2.05 & 0.0429 \\
\hline 7-ketodeoxycholate & 2.79 & $0.0038^{\mathrm{a}}$ \\
\hline Pseudouridine & 0.68 & $0.0013^{\mathrm{a}}$ \\
\hline 2'-deoxycytidine & 1.48 & 0.0036 \\
\hline Methylphosphate & 1.33 & 0.0420 \\
\hline 4-hydroxyhippurate & 1.25 & 0.0152 \\
\hline 4-vinylphenol sulfate & 2.00 & $0.0009^{\mathrm{a}}$ \\
\hline 2,3-butanediol & 3.02 & 0.0387 \\
\hline Gluconate & 0.53 & 0.0060 \\
\hline Equol glucuronide & 0.57 & 0.0068 \\
\hline Equol sulfate & 0.23 & $0.0007^{\mathrm{a}}$ \\
\hline Erythritol & 0.15 & $0.00003^{\mathrm{a}}$ \\
\hline Homostachydrine & 0.16 & $0.0007^{\mathrm{a}}$ \\
\hline $\mathrm{N}$-(2-furoyl)glycine & 4.67 & 0.0062 \\
\hline 4-acetylphenol sulfate & 5.74 & 0.0046 \\
\hline N-methylpipecolate & 0.44 & $0.0038^{\mathrm{a}}$ \\
\hline
\end{tabular}

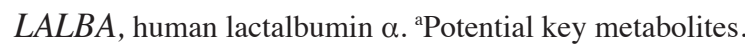

$L A L B A$ and non- $L A L B A$ cows were within the previously established normal range (18) for healthy cows (Table I).

PCA and hierarchical clustering analysis based on detected metabolites. Based on UPLC-MS/MS, LC and GC-MS platforms, a total of 273 compounds with known identity 

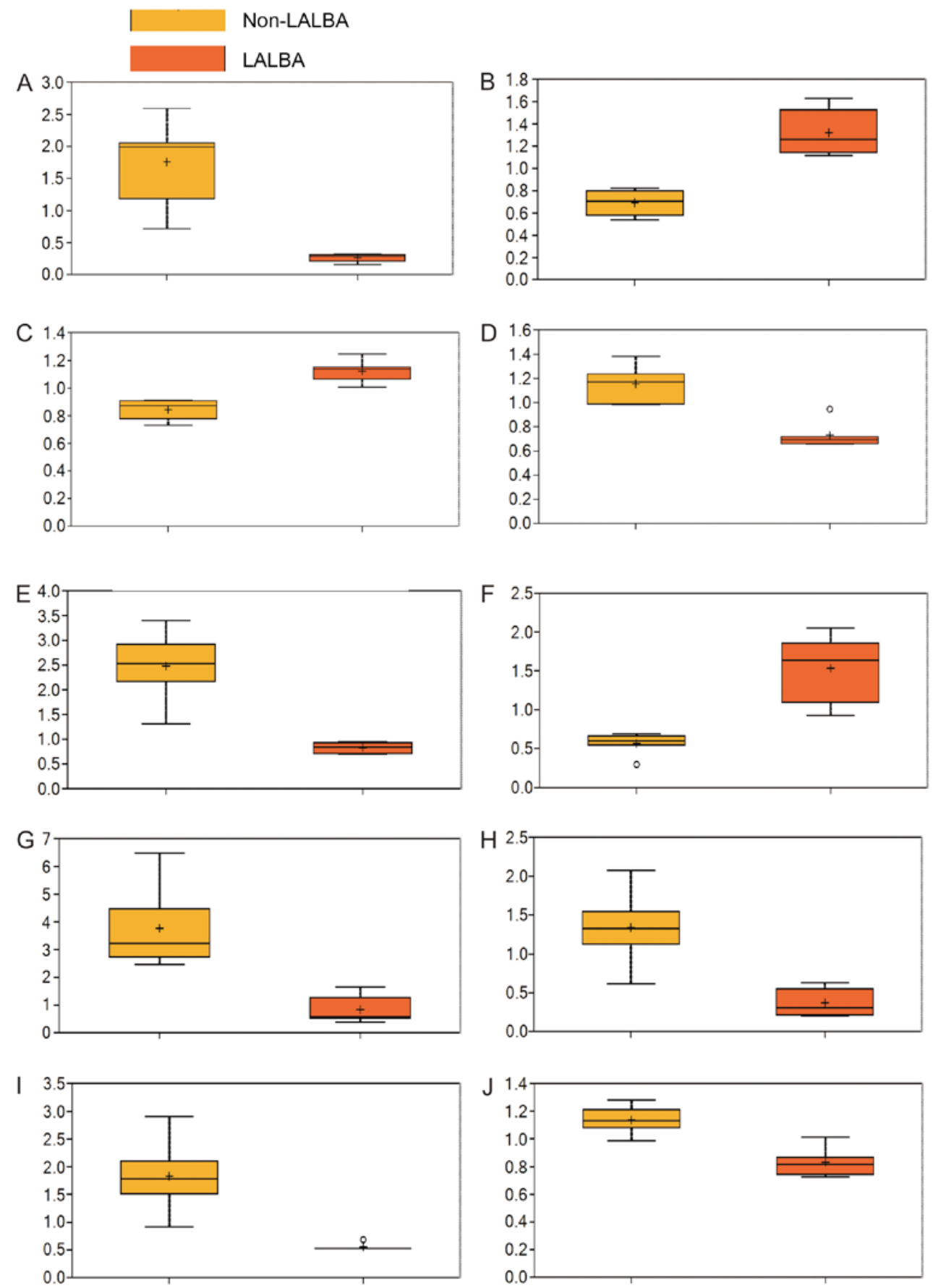

Figure 3. Box plots for the top 10 significantly altered metabolites, including (A) erythritol, (B) 4-hydroxyphenylacetyl glycine, (C) arginine, (D) N-acetylglycine, (E) $\alpha$-hydroxyisocaproate, (F) leucyltryptophan, (G) myristoleate (14:1n5), (H) $\beta$-hydroxyisovalerate (I) phenyllactate and (J) glycerol.

(metabolites) were detected in cow the extracted serum. PCA (Fig. 2A) and hierarchical clustering analysis (Fig. 2B) revealed a distinct separation between $L A L B A$ and non- $L A L B A$ groups. In PCA, the 12 samples could be clearly classified into 2 groups ( $L A L B A$ and non- $L A L B A$ ), and 5 samples from the two groups were closely related (Fig. 2A), which may be due to the small sample size of each group.

Significantly altered metabolites in serum of LALBA cows. Among the 273 detected metabolites, 79 metabolites were found to differ significantly between the $L A L B A$ and non-LALBA groups based on Welch's two-sample t-test (Table II; fold change $\neq 1$ and $\mathrm{P}<0.05$ ), particularly erythritol, 4-hydroxyphenylacetyl glycine, arginine, $\mathrm{N}$-acetylglycine, $\alpha$-hydroxyisocaproate, leucyltryptophan, myristoleate (14:1n5), $\beta$-hydroxyisovalerate, phenyllactate and glycerol (Fig. 3). Additionally, 46 metabolites were significantly increased, whereas 33 metabolites were significantly reduced in the $L A L B A$ group, when compared with the non- $L A L B A$ group.

Random forest analysis. Random forest analysis identified a unique metabolic signature between $L A L B A$ and non- $L A L B A$ groups with a predictive accuracy of $100 \%$ (Fig. 4). Therefore, 


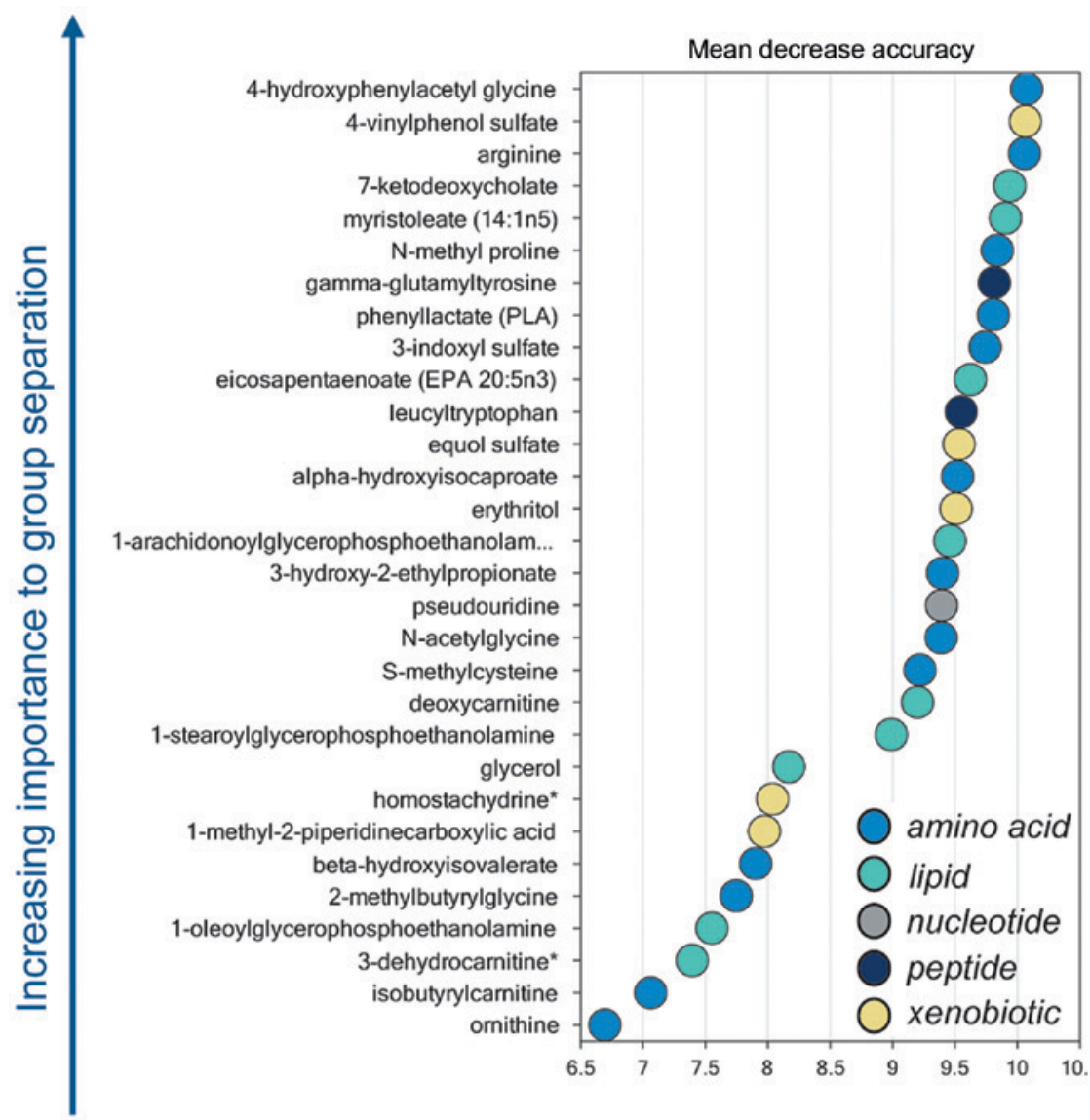

Figure 4. Random forest analysis identified a unique metabolomic signature between the LALBA and non-LALBA group. LALBA, human lactalbumin $\alpha$. Metabolites are rank-ordered by their mean decrease accuracy score. A higher mean decrease accuracy value indicates a greater predictive value.

these 30 metabolites (14 elevated and 16 reduced) were defined as the potential key metabolites (Table II).

Pathway analysis. The significantly altered metabolites and the potential key metabolites were determined to be primarily involved in the Kyoto Encyclopedia of Genes and Genomes (KEGG) pathways, including leucine, isoleucine and valine, tryptophanand and lipid metabolism (Fig. 5). Leucine, isoleucine, and valine, also termed branched chain amino acids (BCAA) were increased in $L A L B A$ serum compared with non- $L A L B A$ controls, whereas their downstream catabolites were reduced, including isobutyrylcarnitine and 2-methylbutyrylcarnitine (Fig. 5A). In the $L A L B A$ serum, tryptophan accumulation was accompanied by reduced levels of indolepropionate and C-glycosyltryptophan; however, elevated levels 3-indoxyl sulfate was also identified (Fig. 5B). In addition, long chain fatty acids including palmitoleate (16:1n7), myristoleate (14:1n5) and myristate (14:0) were reduced in $L A L B A$ serum when compared with non- $L A L B A$ controls. Polyunsaturated fatty acids (PUFAs) including eicosapentaenoate (EPA; 20:5n3), docosapentaenoate (n3 DPA; 22:5n3) and mead acid (20:3n9) were elevated in $L A L B A$ serum (Fig. 5C).

\section{Discussion}

Quantifying the metabolomic profile in serum of cows carrying and expressing $L A L B A$ may provide an insight into the health condition of transgenic $L A L B A$ cows and provide complement evidence for the usage of genetic modification in cows. The present study was conducted to identify the serum metabolic perturbations associated with the presence of human $\angle A L B A$ in cows. A total of 79 metabolites were identified to differ significantly between $L A L B A$ and non- $L A L B A$ groups, 30 of which were defined as potential key metabolites. These metabolites were determined to primarily participate in the metabolism of amino acids and lipids.

In the present study, valine, isoleucine, leucine and tryptophan were found to be significantly increased in the serum of $L A L B A$ cows. Reportedly, BCAA including valine, isoleucine and leucine participate in muscle growth (19) and are associated with physical functions and body composition (20). The supplementation of BCAA or leucine enhances the resistance to fatigue and promotes muscle- and liver-glycogen spares in trained rats (21). Therefore, the accumulation of BCAA may benefit muscle growth and physical functions in $L A L B A$ cows.

Additionally, tryptophan is the precursor of the neurotransmitter serotonin. Serotonin receptors, including HTR1B, HTR2A and HTR2B are expressed in small mammary blood vessels of bovids and serotonin may regulate lactational homeostasis and involution in mammary cells, along with milk yield and composition in dairy cows (22). Tryptophan supplementation may increase plasma tryptophan in heifers and dairy cows, plasma melatonin in heifers and milk yield during morning milking in dairy cows (23). Subcutaneous melatonin treatment during the early dry-off period may improve reproductive performance postpartum in dairy cows, reducing repeat 
A

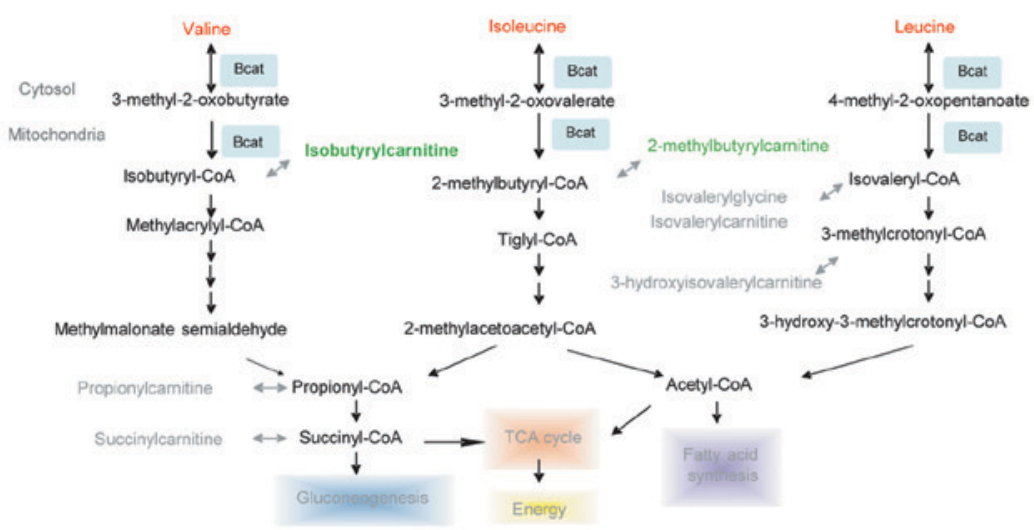

B

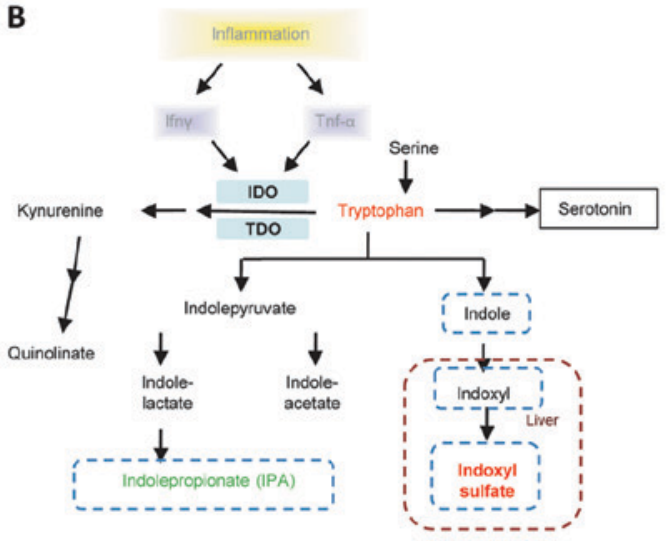

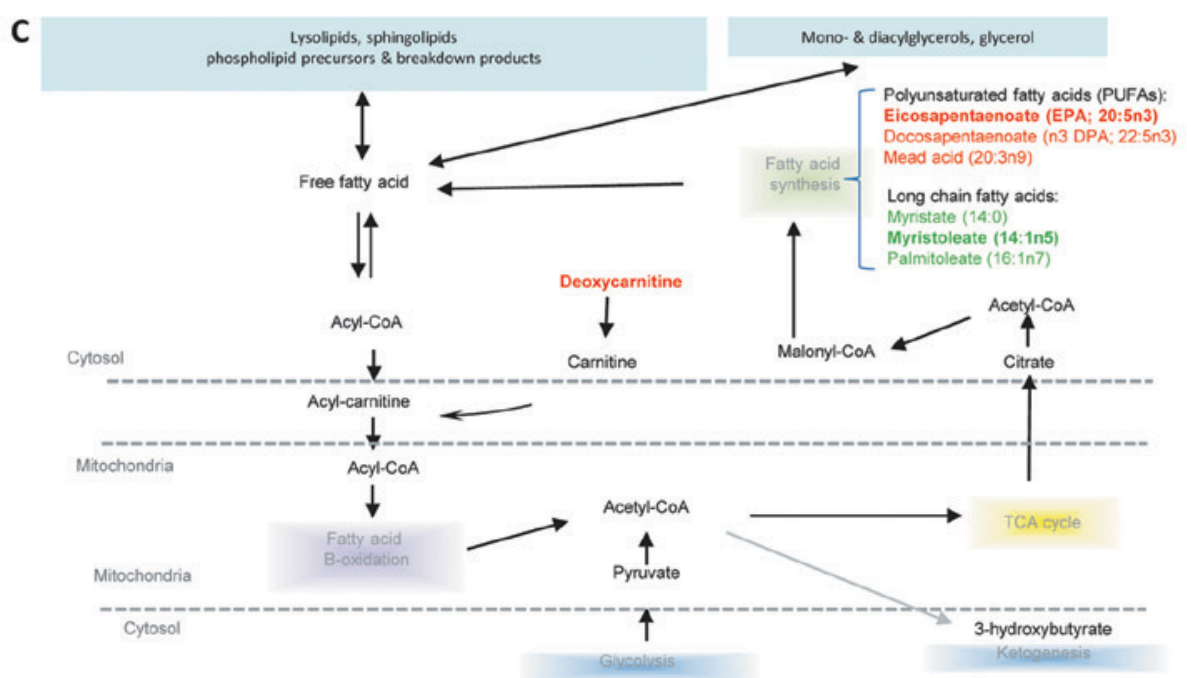

Figure 5. Primary pathways involving significantly altered metabolites. (A) Branched chain amino acids (B) tryptophan and (C) lipid metabolism. Red, increased metabolite; Green, decreased metabolite; Bold, potential key metabolite.

breeding syndrome, the number of days open and pregnancy loss (24). Therefore, an increase in tryptophan level may benefit milk yield and reproductive performance in $L A L B A$ cows.

The present study determined that long chain fatty acids were reduced in $L A L B A$ serum, including myristate (14:0), myristoleate (14:1n5) and palmitoleate (16:1n7). The upregulation of either fatty acid synthesis or lipolysis is a critical feature of tumor metabolism. Saturated fatty acids, such as palmitic acid have pro-inflammatory effects $(25,26)$. The addition of myristic acid, a 14-carbon saturated fatty acid, may enhance the growth of hepatocellular carcinoma cells in ACOT8-knockdown cell lines Huh7 and Hep3B with poor growth (27). Therefore, the decrease of long chain fatty acids, especially myristate, may benefit $L A L B A$ cows via its anti-cancer effect.

PUFAs including EPA, n3 DPA and mead acid were significantly elevated in $L A L B A$ serum, especially EPA, which was a potential key metabolite based on the random forest analysis performed in the present study. EPA may improve health via its anti-cardiovascular diseases, anti-cancer, anti-depression, anti-aging, anti-arthritis, anti-hypertensive, anti-inflammatory, anti-oxidant and insulin-sensitizing effects. It is of note that EPA inhibits the formation of pro-inflammatory prostaglandin $\mathrm{E}_{2}$ from arachidonic acid via competitively binding with cyclooxygenase- 1 and cyclooxygenase- 2 , promoting the production of less-inflammatory prostaglandin $\mathrm{E}_{3}$ (28). Furthermore, EPA induces breast cancer cell apoptosis and inhibits the in vitro growth of breast cancer cells (MDA-MB-231) by 20-25\% at concentrations as low as $25 \mu \mathrm{M}$ and these effects are mediated by the activation of neutral sphingomyelinase, enhancing ceramide formation, membrane bleb formation and p21 expression. Therefore, an increase in EPA may also benefit $L A L B A$ cows.

One of the limitations of the present study was that based on previous studies on metabolite comparison between groups, only $\mathrm{P}<0.05$ and fold change $\neq 1$ were selected as the criteria for the screening of the significantly altered metabolites. However, future studies should perform a correction of $\mathrm{P}$-value to false discovery rate (FDR) and FDR $<0.05$ may lead to more accurate results.

In conclusion, the serum biochemistry indexes of $L A L B A$ cows obtained in the present study were in the normal range, indicating that serum biochemistry characteristics of the cows were not significantly influenced by $L A L B A$. This is consistent with previous studies regarding cloned cattle and their offspring $(4,5)$. In addition, although the serum in $L A L B A$ cows possessed a unique metabolomic signature compared with their non-LALBA counterparts, the accumulation of PUFAs and amino acids, and the decline of long chain saturated fatty acids in $L A L B A$ serum may benefit $L A L B A$ cows. Therefore, 
further investigations should focus on validating these benefits and the corresponding mechanisms.

\section{Acknowledgements}

The present study was funded by the National Science and Technology Major Project (grant no. 2014ZX0801203B). State Key Laboratories for AgroBiotechnology China Agricultural University aided in the sample collection for the present study.

\section{References}

1. Lönnerdal B and Lien EL: Nutritional and physiologic significance of alpha-lactalbumin in infants. Nutr Rev 61: 295-305, 2003.

2. Jackson JG, Janszen DB, Lonnerdal B, Lien EL, Pramuk KP and Kuhlman CF: A multinational study of alpha-lactalbumin concentrations in human milk. J Nutr Biochem 15: 517-521, 2004

3. Wang J, Yang P, Tang B, Sun X, Zhang R, Guo C, Gong G, Liu Y, Li R, Zhang L, et al: Expression and characterization of bioactive recombinant human alpha-lactalbumin in the milk of transgenic cloned cows. J Dairy Sci 91: 4466-4476, 2008.

4. Zhang R, Guo C, Sui S, Yu T, Wang J and Li N: Comprehensive assessment of milk composition in transgenic cloned cattle. PLoS One 7: e49697, 2012.

5. Sui S, Zhao J, Wang J, Zhang R, Guo C, Yu T and Li N: Comparative proteomics of milk fat globule membrane proteins from transgenic cloned cattle. PLoS One 9: e105378, 2014.

6. Clark M, Murray JD and Maga EA: Assessing unintended effects of a mammary-specific transgene at the whole animal level in host and non-target animals. Transgenic Res 23: 245-256, 2014.

7. Hayakawa H, Hirai T, Takimoto A, Ideta A and Aoyagi Y: Superovulation and embryo transfer in Holstein cattle using sexed sperm. Theriogenology 71: 68-73, 2009.

8. Bergmeyer HU, Hørder M and Rej R: International Federation of Clinical Chemistry (IFCC) Scientific Committee, Analytical Section: Approved recommendation (1985) on IFCC methods for the measurement of catalytic concentration of enzymes Part 2. IFCC method for aspartate aminotransferase (L-aspartate: 2-oxoglutarate aminotransferase, EC 2.6.1.1). J Clin Chem Clin Biochem 24: 497-510, 1986.

9. Evans AM, DeHaven CD, Barrett T, Mitchell M and Milgram E: Integrated, nontargeted ultrahigh performance liquid chromatography/electrospray ionization tandem mass spectrometry platform for the identification and relative quantification of the small-molecule complement of biological systems. Anal Chem 81: 6656-6667, 2009.

10. Dehaven CD, Evans AM, Dai H and Lawton KA: Organization of GC/MS and LC/MS metabolomics data into chemical libraries. J Cheminform 2:9, 2010.

11. Liu WW and Hu LP: Principal component analysis and exploratory factor analysis using SAS software package. Zhong Xi Yi Jie He Xue Bao 8: 589-593, 2010 (In Chinese).

12. Kolde R: Pheatmap: Pretty heatmaps. R package version 0.7. 7 .
13. Keselman HJ, Othman AR, Wilcox RR and Fradette K: The new and improved two-sample T test. Psychol Sci 15: 47-51, 2004.

14. Breiman L: Random forests. Machine Learning 45: 5-32, 2001.

15. Svetnik V, Liaw A, Tong C, Culberson JC, Sheridan RP and Feuston BP: Random forest: A classification and regression tool for compound classification and QSAR modeling. J Chem Inf Comput Sci 43: 1947-1958, 2003.

16. Liaw A and Wiener M: The randomforest package. R News 2: 18-22, 2002.

17. Luo W and Brouwer C: Pathview: An R/Bioconductor package for pathway-based data integration and visualization. Bioinformatics 29: 1830-1831, 2013.

18. Ma T, Liu Y, Hao HS, Du WH, Dai YP, Zhao XM, Wang D, Qin T, Zhu HB, Li FD and Wang ZL: Routine hematology and serum biochemistry indexes of transgenic cloned cows carrying human alpha-lactalbumin gene and the recipients. J Gansu Agricultural Univ 5, 2012.

19. Layman DK: The role of leucine in weight loss diets and glucose homeostasis. J Nutr 133: 261S-267S, 2003.

20. Lustgarten $M$ and Fielding R: Circulating branched chain amino acids are associated with body composition and physical function in older adults. FASEB J 29 (1 Suppl): S1038-S1043, 2015.

21. Campos-Ferraz PL, Bozza T, Nicastro $\mathrm{H}$ and Lancha $\mathrm{AH}$ : Distinct effects of leucine or a mixture of the branched-chain amino acids (leucine, isoleucine, and valine) supplementation on resistance to fatigue, and muscle and liver-glycogen degradation, in trained rats. Nutrition 29: 1388-1394, 2013.

22. Hernandez LL, Limesand SW, Collier JL, Horseman ND and Collier RJ: The bovine mammary gland expresses multiple functional isoforms of serotonin receptors. J Endocrinol 203: 123-131, 2009.

23. Kollmann MT, Locher M, Hirche F, Eder K, Meyer HH and Bruckmaier RM: Effects of tryptophan supplementation on plasma tryptophan and related hormone levels in heifers and dairy cows. Domest Anim Endocrinol 34: 14-24, 2008.

24. Garcia-Ispierto I, Abdelfatah A and López-Gatius F: Melatonin treatment at dry-off improves reproductive performance postpartum in high-producing dairy cows under heat stress conditions. Reprod Domest Anim 48: 577-583, 2013.

25. Nieman KM, Kenny HA, Penicka CV, Ladanyi A, Buell-Gutbrod R, Zillhardt MR, Romero IL, Carey MS, Mills GB, Hotamisligil GS, et al: Adipocytes promote ovarian cancer metastasis and provide energy for rapid tumor growth. Nat Med 17: 1498-1503, 2011

26. Tirado-Vélez JM, Joumady I, Sáez-Benito A, Cózar-Castellano and Perdomo G: Inhibition of fatty acid metabolism reduces human myeloma cells proliferation. PloS One 7: e46484, 2012.

27. Hung YH, Chan YS, Chang YS, Lee KT, Hsu HP, Yen MC, Chen WC, Wang CY and Lai MD: Fatty acid metabolic enzyme acyl-CoA thioesterase 8 promotes the development of hepatocellular carcinoma. Oncol Rep 31: 2797-2803, 2014.

28. Calder PC: Polyunsaturated fatty acids and inflammatory processes: New twists in an old tale. Biochimie 91: 791-795, 2009. 